\title{
PROCESS AND SYSTEMS Does telemedicine reduce the carbon footprint of healthcare? A systematic review
}

\author{
Authors: Amy Purohit, ${ }^{A}$ James Smith ${ }^{B}$ and Arthur Hibble ${ }^{C}$
}

In the rapidly progressing field of telemedicine, there is a multitude of evidence assessing the effectiveness and financial costs of telemedicine projects; however, there is very little assessing the environmental impact despite the increasing threat of the climate emergency. This report provides a systematic review of the evidence on the carbon footprint of telemedicine. The identified papers unanimously report that telemedicine does reduce the carbon footprint of healthcare, primarily by reduction in transport-associated emissions. The carbon footprint savings range between 0.70-372 kg CO 2 e per consultation. However, these values are highly context specific. The carbon emissions produced from the use of the telemedicine systems themselves were found to be very low in comparison to emissions saved from travel reductions. This could have wide implications in reducing the carbon footprint of healthcare services globally. In order for telemedicine services to be successfully implemented, further research is necessary to determine context-specific considerations and potential rebound effects.

KEYWORDS: telemedicine, sustainability, e-health, carbon footprint

DOI: $10.7861 /$ fhj.2020-0080

\section{Introduction}

Telemedicine is the use of information and communications technologies (ICT) within the realm of healthcare. The scope of services that fall within the remit of telemedicine is ambiguous. This paper uses the World Health Organization definition of telemedicine, defined as the use of ICT 'for the exchange of valid information for diagnosis, treatment and prevention of disease and injuries, research and evaluation, and for the continuing education of health care providers'.

The applications of telemedicine can be categorised according to type of interaction (clinician-to-patient or clinician-to-clinician) or timing (asynchronous or synchronous). ${ }^{1}$ Asynchronous involves sending pre-recorded information between individuals, whereas

Authors: ${ }^{\text {A }}$ medical student, University of Cambridge, Cambridge, UK; ${ }^{B}$ assistant director of public health studies, University of Cambridge, Cambridge, UK; $C_{\text {tutor }}$ and senior member, Hughes Hall College, Cambridge, UK synchronous is real-time data transmission. The data may be transmitted via a variety of media, such as audio, video or text. This paper will focus on all forms of telemedicine involving direct patient care where the carbon footprint of the telemedicine project is compared to a face-to-face (FTF) scenario.

Telemedicine is a recent development within healthcare. In this decade, there has been an explosion in telemedicine research, focusing on specific medical specialties. The reported advantages include lower financial costs, high patient satisfaction, better rural access, decreased waiting times and fewer missed appointment. ${ }^{2-7}$ There is less available evidence from primary care; however, there are positive findings in primary care chronic disease management. ${ }^{8-10}$ The main disadvantages are erosion of the clinician-patient relationship and concerns around quality of care. In terms of clinicianpatient relationship, this concern arises particularly from elderly patients and healthcare providers themselves; however, acceptance has been shown to be increasing. ${ }^{6,11,12}$ There are mixed reports on the quality of care provided by telemedicine; some sources report improved or maintained standards of care, whereas others found a reduction in quality of care compared to FTF scenarios. ${ }^{9,13-19}$

In spite of the extensive research into the effectiveness, cost and perceptions of telemedicine, there have been few contributions assessing the environmental impact; despite many previous studies stating a reduction in travel time and the increasing awareness of environmental concerns within society. ${ }^{7,20-23}$

In a world where climate change has been named as one of the biggest threats to human health, the healthcare sector continues to significantly contribute to greenhouse gas (GHG) emissions. ${ }^{24}$ Health Care Without Harm estimated the global carbon footprint of healthcare to be 2 gigatons of carbon dioxide equivalents $\left(\mathrm{CO}_{2} \mathrm{e}\right)$ in 2014 , equating to $4.4 \%$ of global net emissions; transport contributed $7 \%$ of this total. ${ }^{25}$

From a UK perspective, the estimated carbon footprint of the NHS in England was 25.0 megatons of $\mathrm{CO}_{2} \mathrm{e}$ in $2019 .{ }^{26}$ The NHS launched the 'For a Greener NHS' programme in January 2020, and has produced a Net Zero Report outlining the interventions needed to reach its target of being net carbon zero by $2050 .^{26}$ Travel accounts for $10 \%$ of NHS' GHG emissions and, in 2008, an estimated $5 \%$ of all road travel was attributable to the $\mathrm{NHS}^{26,27}$ Telemedicine provides an exciting prospect for potential reduction in the NHS' contribution to climate change. A 2018 NHS Midlands and Lancashire commissioned report estimated that the West Midlands 
could reduce emissions by $533,535 \mathrm{~kg} \mathrm{CO} 2$ e annually by shifting $15 \%$ of all hospital follow-up consultations to telemedicine. ${ }^{28}$

\section{Methods}

A review of the published works relating to the carbon footprint of telemedicine was carried out using the databases MEDLINE, Embase and Scopus. The search strategy is documented in supplementary material S1, Table S1.

The searches were carried out by two researchers between 10 May 2020 and 14 May 2020, and there were no limitations in terms of publication date. The publications were then screened for duplications. The inclusion criterium was for the publication to be a primary research study considering the carbon footprint of telemedicine programmes. The exclusion criteria were:

> publications not involving direct patient care

$>$ veterinary or dentistry publications

$>$ non-English language publications

$>$ publications modelling theoretical carbon footprint savings from future adoption of telemedicine

$>$ publications without primary data.

There were no limitations on research methods. After having been screened for suitability, the publications were divided into three categories for analysis: telephone synchronous, video synchronous and asynchronous. The telephone consultations were not divided based on VoIP (Voice over Internet Protocol) versus mobile telephone or landline calls, since this information was not available in all of the publications.

In order to compare the studies, the total $\mathrm{CO}_{2}$ e reductions were divided by the number of consultations to calculate emissions reduction per consultation. Travel distance saved was compared with the carbon footprint reduction per consultation, and linear regressions were used to quantify the strength of this correlation.

\section{Results}

\section{Study selection}

The PRISMA statement (Preferred Reporting Items for Systematic Reviews and Meta-Analyses) was used to screen the literature, illustrated in Fig 1. ${ }^{29}$

This literature search produced 65 results, 11 of which were found to be duplicates. After assessment against exclusion and inclusion criteria, 14 of these publications were found to be relevant to the assigned question.

\section{Study comparison}

Fig 2 illustrates the carbon footprint saved versus the average travel distance saved (Table 1). This positive correlation highlights that the carbon footprint saving is primarily due to travel reduction. The blue trendline considers only the studies which measured road travel, and there is strong positive correlation $\left(r^{2}=0.9973 ; p=3.78 \times 10^{-14}\right)$. The results of this linear regression are shown in supplementary material S1, Table S2. The two studies examining air travel do not appear to fit this pattern (shown in yellow). The strong congruence shown across road travel studies gives confidence in the reliability and thoroughness of the literature.

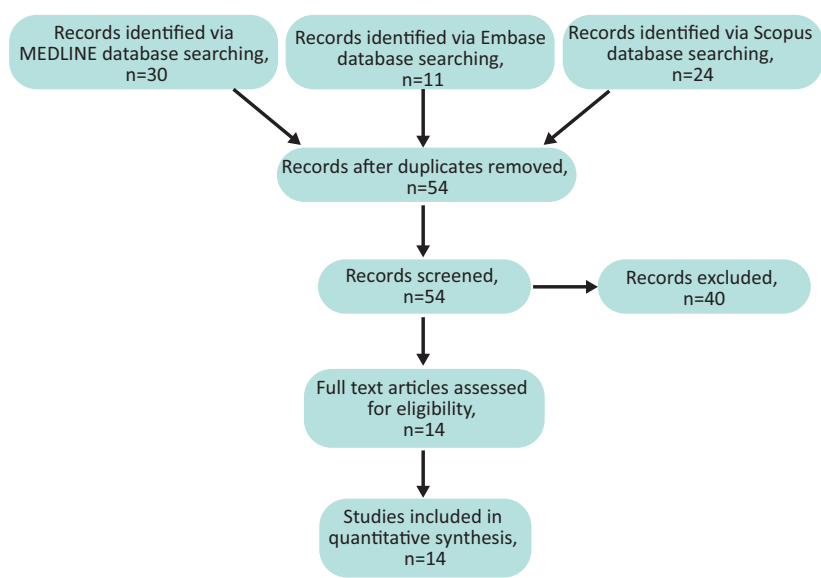

Fig 1. PRISMA diagram showing literature search results.

\section{Telephone synchronous}

There were four examples found of telephone synchronous papers. Two studies from the UK assessed a virtual urology clinic in London. ${ }^{30,31}$ Both studies measured carbon footprints by the distance saved from patients' home addresses to the hospital in which the FTF appointment would have otherwise occurred. They calculated two different scenarios; assuming every patient either drove using a 1,800 cc petrol car or took the underground train. In Fig 2, the values for the car scenarios were used since this is the mode of transport primarily used in the other studies. Miah et al found an average distance saving of $18.2 \mathrm{~km}$ per patient, correlating with savings per consultation of $0.86 \mathrm{~kg} \mathrm{CO}_{2} \mathrm{e}$ (underground scenario) and $3.55 \mathrm{~kg} \mathrm{CO}_{2} \mathrm{e}$ (car scenario). ${ }^{30} \mathrm{MJ}$ Connor et al assessed 1,008 patients and found an average saving of $15.0 \mathrm{~km}$ per patient, correlating to a carbon footprint reduction of $0.70 \mathrm{~kg} \mathrm{CO} 2 \mathrm{e}$ (underground scenario) and $2.93 \mathrm{~kg} \mathrm{CO}_{2} \mathrm{e}$ (car scenario). ${ }^{31}$ It is unknown whether the individual patients overlapped between these two studies due to their overlapping time frames. This is a relatively low $\mathrm{CO}_{2}$ e saving due to short travel distances in a densely populated region.

A Connor et al assessed telephone follow-up appointments postrenal transplant surgery. ${ }^{32}$ They examined 30 patients attending

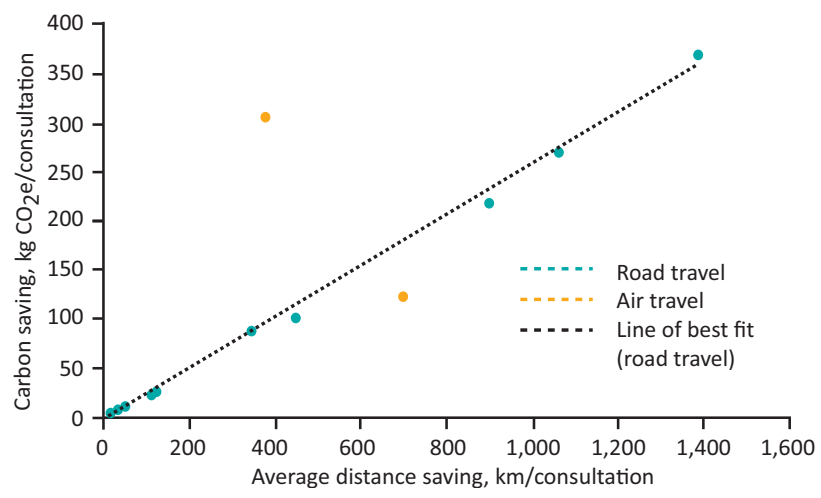

Fig 2. Carbon footprint against travel distance savings of telemedicine interventions. 
Table 1. Distance and carbon savings of telemedicine studies

\begin{tabular}{|c|c|c|c|}
\hline Study & Study region & $\begin{array}{l}\text { Average distance saving } \\
\text { (km/consultation) }\end{array}$ & $\begin{array}{l}\text { Carbon footprint } \\
\text { (kg CO2e/consultation) }\end{array}$ \\
\hline Beswick et al (2014) & California, USA & 1,387 & 372 \\
\hline Connor A et al (2011) & Warwickshire, UK & 39.3 & 8.05 \\
\hline \multirow[t]{2}{*}{ Connor MJ et al (2019) } & London, UK & 15.0 & 2.93 (car) \\
\hline & & & 0.70 (underground train) \\
\hline Dorrian et al (2009) & Scotland, UK & 698 & 123 (air) \\
\hline Dullet et al (2017) & California, USA & 447 & 102 \\
\hline \multirow[t]{2}{*}{ Holmner et al (2014) } & Västerbotten, Sweden & 346 & 87.4 (Leduc LCA model) \\
\hline & & & 176 (Lenzen LCA model) \\
\hline Masino et al (2010) & Ontario, Canada & 901 & 220 \\
\hline \multirow[t]{2}{*}{ Miah et al (2019) } & London, UK & 18.2 & 3.55 (car) \\
\hline & & & 0.86 (underground train) \\
\hline Oliveira et al (2013) & Alentejo, Portugal & 111 & 22.0 \\
\hline Paquette et al (2019) & Michigan, USA & 50.2 & 11.2 \\
\hline Robinson et al (2017) & Texas, USA & 1,061 & 271 \\
\hline Vidal-Alaball et al (2019) & Catalonia, Spain & 21.3 & 3.25 \\
\hline Whetten et al (2019) & New Mexico, USA & 381 & 306 (air) \\
\hline Wootton et al (2010) & Scotland, UK & 126 & 26.9 \\
\hline
\end{tabular}

$\mathrm{LCA}=$ life cycle assessment.

two consecutive telephone appointments. Calculating travel distances from home addresses, also taking into account mode of transport and vehicle specifications; the mean saving was $39.3 \mathrm{~km}$, equating to $8.05 \mathrm{~kg} \mathrm{CO}_{2}$ e per consultation.

Robinson et al assessed the environmental savings from presurgical telephone consultations in Texas. ${ }^{33}$ There was only one tertiary centre providing this surgery, so large distances were travelled for surgical eligibility. Using ZIP codes, this study found that the average mileage saved was $1,061 \mathrm{~km}$. They made the assumption of an average car, so not accounting for other methods of transport and vehicle specifications. The reduction in carbon footprint was calculated as $271 \mathrm{~kg} \mathrm{CO}$ e per consultation. This prospective study found there to be a correlation between increased travel distance and increased likelihood of choosing telemedicine over FTF appointments.

One limitation of these telephone synchronous studies is that they do not assess the carbon footprint of the running of the telephone service, which would have to be subtracted from the $\mathrm{CO}_{2} \mathrm{e}$ estimation.

\section{Video synchronous}

There were nine examples of video synchronous telemedicine. Since videoconferencing equipment is more specialised and therefore less common within people's homes, many of the video consultations occurred at an intermediate telemedicine site. Three of these sources additionally accounted for the carbon footprint of the telemedicine equipment of both of the clinician and patient devices.

Holmner et al assessed videoconferencing for telerehabilitation in Sweden. As well as looking at distances from the patients' homes to the hospital, a comprehensive life cycle assessment (LCA) was carried out to estimate the carbon footprint of the videoconferencing equipment. ${ }^{34}$ This was a 'cradle to grave' assessment based on the model in Ong et al, which included energy consumption of equipment during the use-phase as well as emissions generated during design, manufacturing and disposal of equipment. ${ }^{35}$ LCAs of car travel were also included, based on average characteristics of European cars. From the 238 appointments at the hand and plastics surgery clinic, a total travel distance of $82,310 \mathrm{~km}$ was saved, giving a range of $87.4-176 \mathrm{~kg}$ $\mathrm{CO}_{2} \mathrm{e}$ per consultation saved using telemedicine. This range was due to the use of two different LCAs of vehicles. In Fig 2, $87.4 \mathrm{~kg}$ $\mathrm{CO}_{2} \mathrm{e}$ was used since this value arises from the most recent LCA by Leduc et al, reflecting recent increases in energy efficiency of cars. ${ }^{36}$ An important conclusion of this paper is that the carbon footprint of the telemedicine equipment is small compared to the carbon footprint of travel, at $1.86-8.43 \mathrm{~kg} \mathrm{CO}_{2}$ e per hour consultation.

Two additional studies consider the energy usage of the videoconferencing equipment, but do not include LCAs of emissions produced during production and disposal of equipment. Masino et al looked at telemedicine appointments in Ontario using estimated distances from the patient address to the telemedicine site, as compared with the hospital. ${ }^{37}$ There was a mean saving of $901 \mathrm{~km}$ per consultation. The environmental cost of the telemedicine equipment was found to be very low, at $0.04 \mathrm{~kg} \mathrm{CO}_{2} \mathrm{e}$ per 1-hour consultation. The total $\mathrm{GHG}$ saving was $220 \mathrm{~kg} \mathrm{CO} 2 \mathrm{e}$ per consultation. Whetten et al produced a similar result of 0.052 $\mathrm{kg} \mathrm{CO}_{2}$ e per 1-hour consultation. ${ }^{38}$ This study looked at neurology video consultations from 12 rural hospital sites to a large hospital in New Mexico, which avoided unnecessary helicopter air ambulance flights. $\mathrm{CH}_{4}$ (methane), $\mathrm{CO}_{2}$ and $\mathrm{N}_{2} \mathrm{O}$ (nitrous oxide) emissions were used to calculate $\mathrm{CO}_{2} \mathrm{e}$. This saved $381 \mathrm{~km}$ per consultation, equating to $306 \mathrm{~kg} \mathrm{CO}$ e. 
Dullet et al investigated the carbon footprint of University of California Davis Health System's (UCDHS) outpatient telemedicine service. ${ }^{39}$ There were 157 telemedicine sites across California from which these services could be accessed. Average one-way distance to telemedicine sites was $27.4 \mathrm{~km}$ compared with a potential $251 \mathrm{~km}$ to the UCDHS. A total of $1,969,000 \mathrm{~kg} \mathrm{CO} 2 \mathrm{e}$ was saved over 19,246 consultations, corresponding to $102 \mathrm{~kg} \mathrm{CO}_{2}$ per consultation. A similar large-scale study in Portugal by Oliveira et al assessed 20,824 video consultations. ${ }^{40}$ Estimates of travel distances were made using survey data on distance travelled and mode of transport. It concluded that without video consultations, patients would have travelled an extra $2,313,819 \mathrm{~km}$, increasing the carbon footprint by $455,000 \mathrm{~kg} \mathrm{CO}_{2} \mathrm{e}\left(22 \mathrm{~kg} \mathrm{CO}_{2} \mathrm{e}\right.$ per consultation). This gave a retrospectively calculated reduction of 95\% in GHG emissions.

Paquette et al assessed video consultations from one vascular surgeon in Michigan. ${ }^{41}$ Using average vehicle emissions, the average distance saved travelling to the telemedicine site compared with the hypothetical distance to the hospital was calculated to be $50.2 \mathrm{~km}$ per consultation, equating to $11.2 \mathrm{~kg} \mathrm{CO}_{2} \mathrm{e}$.

Wootton et al assessed a videoconferencing tool used in nurseled minor injuries units in Grampian, Scotland. ${ }^{42}$ This allowed clinicians to ask for advice from emergency doctors in Aberdeen, preventing unnecessary transfer in $90-95 \%$ of cases. This was estimated to avoid $260,000 \mathrm{~km}$ of travel, or $26.9 \mathrm{~kg} \mathrm{CO} \mathrm{CO}_{2} \mathrm{e}$ per consultation.

Two studies investigated the use of videoconferencing for head and neck cancer assessment. ${ }^{35,36}$ In Dorrian et al, doctors on the Shetland Islands performed laryngoscopy which was viewed live by a consultant in Aberdeen. ${ }^{43}$ The carbon footprint savings were calculated from both the road and air segments of the journey (a $698 \mathrm{~km}$ round-trip) estimated to reduce emissions by $123 \mathrm{~kg} \mathrm{CO}_{2}$ e per consultation. In Beswick et al, 21 patients were assessed for head and neck cancer over 39 videoconferences. ${ }^{44}$ This occurred with healthcare professionals at the patient's home, providing real time nasopharyngoscopy, which was viewed live by a surgeon at a hospital in California. The roundtrip distance saved was $1,387 \mathrm{~km}$ road travel per consultation, equating to $372 \mathrm{~kg} \mathrm{CO} 2$ e. One limitation in both studies is that the travel distances of the healthcare professionals were not accounted for.

\section{Non-synchronous}

The literature search produced only one example of nonsynchronous telemedicine. Vidal-Alaball et al looked at primary care referrals to telemedicine services in Catalan. ${ }^{45}$ Rather than using exact patient addresses, distances were calculated from the primary care centres to secondary care centres and assumed every patient travelled by car. The mean distance saved was $21.3 \mathrm{~km}$, equating to $3.25 \mathrm{~kg} \mathrm{CO}_{2}$ e per patient.

\section{Discussion}

The studies in this review consistently report that telemedicine reduces the carbon footprint of healthcare as compared with FTF scenarios. This reported benefit was primarily through travel-associated savings which greatly outweighed the carbon footprint of the telemedicine equipment. The savings ranged from 0.70 to $372 \mathrm{~kg} \mathrm{CO}_{2}$ e per consultation but were highly context specific.
It is important to consider the differences between media sources within telemedicine. Videoconferencing has a higher energy consumption compared with telephone consultations, so it can be assumed that the carbon footprint would be higher. An advantage of telephone appointments is that the majority of people worldwide have access to a telephone, whereas videoconferencing may require travel to a telemedicine site. ${ }^{46}$ However, comparisons between the two media sources have found videoconferencing to be safer, with more favourable outcomes and better clinician decision making. ${ }^{47-50}$

The carbon footprint savings were highly dependent on the inter-related factors of medical specialty, geography and time. The higher the level of specialisation seemed to correspond with a greater reduction in travel, since specialised centres serviced a wider geographic region. For example, in Beswick et al, there was only one tertiary centre providing this service for veterans in southwest USA, therefore travel reductions were large. ${ }^{44}$ This implies that the extent of carbon footprint reduction will be dependent on the population density of the region, as well as on transport infrastructure.

There are limitations arising from variance in methodology within these research papers. There is variation in how travel and carbon footprint has been modelled. In terms of modes of transport, the majority of studies assumed the mode of transport to be a car, with assumed average characteristics. Considering the air travel scenarios, emissions from flights are highly dependent on the size and type of aircraft. The primary source of GHGs from travel is carbon dioxide, which was consistently accounted for in every study. However, some studies provided a more comprehensive assessment of $\mathrm{GHG}$, also assessing $\mathrm{CH}_{4}$ and $\mathrm{N}_{2} \mathrm{O} \cdot{ }^{37,38}$ Another factor to consider is double consulting; $\mathrm{a}$ situation where a teleconsultation is inadequate, necessitating the need for a further FTF consultation. This scenario increases the net carbon emissions. Future studies should aim to incorporate carbon emissions from subsequent FTF consultations in order to more accurately represent net carbon savings.

There is a limitation in that the majority of studies did not include the carbon footprint of the telemedicine service; but when assessed, this was found to be low in comparison to travel carbon footprint. The most comprehensive LCA, carried out by Holmner et al, estimated that the studied telerehabilitation service became carbon cost-effective where the patient travel distance was over $7.2 \mathrm{~km} .{ }^{34}$ This again highlights the variance in net savings depending on travel distance; however, all of the studies analysed in this paper had a travel distance of over $7.2 \mathrm{~km}$. Fig 2 highlights the low significance of the telemedicine carbon footprint, since there was congruence between road travel studies regardless of whether they included this aspect or not. Another limitation is that the studies assumed that every telemedicine appointment would otherwise have taken place at the specified hospital. This may not have been the case; patients may have otherwise been referred to less specialised local hospitals or may have chosen not to attend an appointment due to large travel distances and costs. Therefore, the reductions in travel may be an overestimate.

This review assessed only the direct carbon footprint of telemedicine; there may be rebound effects to consider. It has not been determined what the time and money saved by individuals and healthcare organisations would have been used for instead. If these alternate activities were high carbon generating, then there is a risk that much of the savings could be undermined. However, since there is likely to be an increasing 
drive to decarbonise across all sectors, this argument should not be an impediment against reducing the carbon footprint of healthcare services. There are other environmental aspects in addition to carbon footprint which have not been considered in this review; for example, some of the studies additionally quantified the production of non-GHG gases which may be additionally harmful to health. ${ }^{37-39,41,45}$ Furthermore, reductions in car travel could reduce health harms from road traffic accidents and encourage increased walking and cycling.

There are additionally limitations within this systematic review. Although a comprehensive search strategy was used, it is possible that not all relevant studies were found. As this subject sits across disciplines of healthcare, technology and environmental sustainability, ensuring exhaustive pick up is challenging. Due to the limited number of relevant studies found, it was not possible to scrutinise and exclude on quality of methodology. There is a limitation in the small study sample size; however, the strong congruence found in the data may suggest reliability of these sources.

The implications of this paper will be dependent on the country being considered. Using the UK as an example, telemedicine could greatly reduce travel-associated emissions. In 2011-2012, there was found to be an average of $8.7 \mathrm{~km}$ one-way from homes to the nearest emergency centre in England $(17.6 \mathrm{~km}$ in rural areas compared with $7.6 \mathrm{~km}$ in urban areas). ${ }^{51}$ In 2016-2017, 93.9 million outpatient appointments were attended by patients in England. ${ }^{52}$ Since travel accounts for $10 \%$ of NHS carbon footprint, the widespread adoption of telemedicine services within the NHS could lead to huge emission reductions. ${ }^{26}$ The studies in this paper all focused on secondary or tertiary care; however telemedicine may also have environmental savings within general practice. In the year from November 2017 to October 2018, there were an estimated 308 million general practice appointments, $82 \%$ of which were FTF appointments. ${ }^{53}$

In the current COVID-19 pandemic, the use of telemedicine is proving indispensable to remotely assess patients, both in diagnosis of COVID-19 as well as ongoing management of chronic disease. ${ }^{54,55}$ This has been adopted across both primary and secondary care. ${ }^{56,57}$ This may accelerate the uptake of telemedicine globally, and increase acceptance of it among clinicians and patients alike.

\section{Conclusion}

The studies found in this review have unanimously reported that the use of telemedicine services leads to a reduction in the carbon footprint of healthcare. There was found to be a strong relationship between the carbon footprint saving and the average travel distance saving; highlighting that the majority of environmental reductions arise from reduction in travel to appointments. The consistency between studies and the scientific plausibility of the findings can give us confidence in the overall validity of our conclusions.

Our review suggests that telemedicine could play a valuable role in the transition to a net carbon-zero healthcare system. Further research is necessary to understand how to implement telemedicine within specific contexts of specialty and geographic region in order to maximise clinical and environmental benefits. The rebound effects of these telemedicine programmes, as well as the impact of double consulting, need to be further explored. The majority of the studies analysed did not include LCAs for the telemedicine equipment or for the modes of transport, therefore missing out a component of the carbon footprint. Future studies should aim to include these LCAs in order to produce more accurate estimates of carbon footprint which can be used to assess whether these programmes are carbon cost-effective. As for any new intervention in healthcare, multiple factors need to be considered including clinical and cost effectiveness, safety and equity, all in relation to a local context. It is into this mix that environmental considerations such as carbon footprint need to be understood.

\section{Supplementary material}

Additional supplementary material may be found in the online version of this article at www.rcpjournals.org/fhj:

S1 - Search terms and regression statistics.

\section{Conflicts of interest}

Dr James Smith reports personal fees from Trumpington Street Medical Practice, grants and personal fees from NHS England, personal fees from World Health Organization Europe, personal fees from Better Value Healthcare Ltd, personal fees from Cambridgeshire County Council, personal fees from University of Cambridge and its colleges, outside the submitted work; and he is married to a practicing GP in Cambridgeshire.

\section{References}

1 World Health Organization. Telemedicine: Opportunities and developments in Member States. Geneva: WHO, 2010.

2 Kruse CS, Krowski N, Rodriguez B et al. Telehealth and patient satisfaction: A systematic review and narrative analysis. BMJ Open 2017;7:e016242. https://doi.org/10.1136/ bmjopen-2017-016242

3 Emami E, Kadoch N, Homayounfar et al. Patient satisfaction with e-oral health care in rural and remote settings: A systematic review protocol. Syst Rev 2017;6:174.

4 Orlando JF, Beard M, Kumar S. Systematic review of patient and caregivers' satisfaction with telehealth videoconferencing as a mode of service delivery in managing patients' health. PLOS One 2019;14:e221848.

5 Mounessa JS, Chapman S, Braunberger T et al. A systematic review of satisfaction with teledermatology. J Telemed Telecare 2018;24:263-70.

6 Bashshur RL, Howell JD, Krupinski EA et al. The empirical foundations of telemedicine interventions in primary care. Telemed J $E$ Health 2016;22:342-75.

7 Le Goff-Pronost M, Mourgeon B, Blanchère JP et al. Real-world clinical evaluation and costs of telemedicine for chronic wound management. Int J Technol Assess Health Care 2018;34:567-75.

8 Orozco-Beltran D, Sánchez-Molla M, Sanchez J], Mira J]. Telemedicine in primary care for patients with Chronic conditions: The valcrònic quasi-experimental study. J Med Internet Res 2017;19:e400.

9 Kroenke K, Krebs EE, Wu J et al. Telecare collaborative management of chronic pain in primary care a randomized clinical trial. JAMA 2014:312:240-8.

10 Beste LA, Glorioso TJ, Ho PM et al. Telemedicine specialty support promotes hepatitis $\mathrm{c}$ treatment by primary care providers in the department of veterans affairs. Am J Med 2017;130:432-8.e3.

11 Ulrich O, Marlene B, Silvan T. [Telemedicine and the ageing population]. Ther Umsch 2015;72:567-75.

12 Waller M, Stotler C. Telemedicine: a primer. Curr Allergy Asthma Rep 2018;18:54. 
13 Guaiana G, Mastrangelo ], Hendrikx S, Barbui C. A systematic review of the use of telepsychiatry in depression. Community Ment Health J 2020.

14 Zhang W, Cheng B, Zhu W et al. Effect of telemedicine on quality of care in patients with coexisting hypertension and diabetes: a systematic review and meta-analysis. Telemed J E Health 2020 [Epub ahead of print].

15 Lazarus G, Permana AP, Nugroho SW et al. Telestroke strategies to enhance acute stroke management in rural settings: A systematic review and meta-analysis. Brain Behav 2020;10:e01787.

16 Chen L, Cheng L, Gao W et al. Telemedicine in chronic wound management: Systematic review and meta-analysis. JMIR Mhealth Uhealth 2020;8:e15574.

17 Hammersley V, Donaghy E, Parker R et al. Comparing the content and quality of video, telephone, and face-to-face consultations: A non-randomised, quasi-experimental, exploratory study in UK primary care. Br J Gen Pract 2019;69:e595-604.

18 Ullah W, Pathan SK, Panchal A et al. Cost-effectiveness and diagnostic accuracy of telemedicine in macular disease and diabetic retinopathy: A systematic review and meta-analysis. Medicine (Baltimore) 2020;99:e20306.

19 Wang Y, Min J, Khuri J et al. Effectiveness of mobile health interventions on diabetes and obesity treatment and management: Systematic review of systematic reviews. JMIR Mhealth Uhealth 2020;8:e15400.

20 Kessler EA, Sherman AK, Becker ML. Decreasing patient cost and travel time through pediatric rheumatology telemedicine visits. Pediatr Rheumatol Online J 2016;14:54

21 Russo JE, McCool RR, Davies L. VA Telemedicine: An Analysis of Cost and Time Savings. Telemed J E Health 2016;22:209-15.

22 Kahn EN, La Marca F, Mazzola CA. Neurosurgery and telemedicine in the united states: assessment of the risks and opportunities. World Neurosurg 2016;89:133-8.

23 Ipsos MORI. Solving the environment is everyone's problem. Ipsos MORI, 2020. www.ipsos.com/ipsos-mori/en-uk/solving-environmenteveryones-problem

24 World Health Organization. Climate change and health. WHO, 2018. www.who.int/news-room/fact-sheets/detail/climate-changeand-health [Accessed 16 April 2020].

25 Karliner ], Slotterback S, Boyd R, Ashby B, Steele K. Health care's climate footprint: how the health sector contributes to the global climate crisis and opportunities for action. Health Care Without Harm, 2019.

26 NHS. Delivering a 'net zero' National Health Service. NHS, 2020. www.england.nhs.uk/greenernhs/wp-content/uploads/ sites/51/2020/10/delivering-a-net-zero-national-health-service.pdf [Accessed 20 October 2020].

27 Mayor S. NHS should bring in measures to reduce its carbon footprint, BMA says. BMJ 2008;336:740.

28 The Strategy Unit. The potential economic impact of virtual outpatient appointments in the west midlands: a scoping study. NHS Midlands and Lancashire Commissioning Support Unit, 2018. www.strategyunitwm.nhs.uk/sites/default/files/2018-11/180813_ Economic \% 20Impact \% 20of \% 200P\% 20Appointments \% 20 for $\% 20$ WM $\%$ 20CCGs FINAL.pdf [Accessed 21 October 2020].

29 Moher D, Liberati A, Tetzlaff ] et al. Preferred reporting items for systematic reviews and meta-analyses: The PRISMA statement. PLoS Med 2009;6:e1000097.

30 Miah S, Dunford C, Edison M et al. A prospective clinical, cost and environmental analysis of a clinician-led virtual urology clinic. Ann $R$ Coll Surg Engl 2019;101:30-4.

31 Connor M], Miah S, Edison MA et al. Clinical, fiscal and environmental benefits of a specialist-led virtual ureteric colic clinic: a prospective study. BJU Int 2019;124:1034-9.

32 Connor A, Mortimer F, Higgins R. The follow-up of renal transplant recipients by telephone consultation: Three years experience from a single UK renal unit. Clin Med 2011;11:242-6.
33 Robinson JD, Prochaska JD, Yngve DA. Pre-surgery evaluations by telephone decrease travel and cost for families of children with cerebral palsy. SAGE Open Med 2017;5:2050312117720046.

34 Holmner A, Ebi KL, Lazuardi L, Nilsson M. Carbon footprint of telemedicine solutions-unexplored opportunity for reducing carbon emissions in the health sector. PloS One 2014;9:e105040.

35 Ong D, Moors T, Sivaraman V. Complete life-cycle assessment of the energy/CO2 costs of videoconferencing vs face-to-face meet ings. 2012 IEEE Online Conference on Green Communications (GreenCom) 2012:50-55.

36 Leduc G, Mongelli I, Uihlein A, Nemry F. How can our cars become less polluting? An assessment of the environmental improvement potential of cars. Transport Policy 2010;17:409-19.

37 Masino C, Rubinstein E, Lem L, Purdy B, Rossos PG. The impact of telemedicine on greenhouse gas emissions at an academic health science center in Canada. Telemed J E Health 2010;16:973-6.

38 Whetten J, Montoya J, Yonas H. ACCESS to better health and clear skies: telemedicine and greenhouse gas reduction. Telemed J $E$ Health 2019:25:960-5.

39 Dullet NW, Geraghty EM, Kaufman T et al. Impact of a university-based outpatient telemedicine program on time savings, travel costs, and environmental pollutants. Value Health 2017;20:542-6.

40 Oliveira TC, Barlow ], Gonçalves L, Bayer S. Teleconsultations reduce greenhouse gas emissions. J Health Serv Res Policy 2013;18:209-14.

41 Paquette S, Lin JC. Outpatient telemedicine program in vascular surgery reduces patient travel time, cost, and environmental pollutant emissions. Ann Vasc Surg 2019;59167-72.

42 Wootton R, Tait A, Croft A. Environmental aspects of health care in the Grampian NHS region and the place of telehealth. J Telemed Telecare 2010;16:215-20.

43 Dorrian C, Ferguson J, Ah-See K et al. Head and neck cancer assessment by flexible endoscopy and telemedicine. J Telemed Telecare 2009;15:118-21.

44 Beswick DM, Vashi A, Song Y et al. Consultation via telemedicine and access to operative care for patients with head and neck cancer in a Veterans Health Administration population. Head and Neck 2016;38:925-9.

45 Vidal-Alaball J, Franch-Parella J, Seguí FL, Cuyas FG, Pena JM. Impact of a telemedicine program on the reduction in the emission of atmospheric pollutants and journeys by road. Int J Environ Res Public Health 2019;16:4366.

46. Statista. Number of mobile phone users worldwide 2015 to 2020. Statista, 2016. www.statista.com/statistics/274774/forecast-ofmobile-phone-users-worldwide [Accessed 13 May 2020].

47 Capampangan D], Wellik KE, Bobrow B] et al. Telemedicine versus telephone for remote emergency stroke consultations: A critically appraised topic. Neurologist 2009;15:163-6.

48 Poon WS, Leung CHS, Lam MK et al. The comparative impact of video consultation on neurosurgical health services. Int J Med Inform 2001;62:175-80.

49 Bolle SR, Larsen F, Hagen O, Gilbert M. Video conferencing versus telephone calls for team work across hospitals: A qualitative study on simulated emergencies. BMC Emerg Med 2009;9:22.

50 Seuren LM, Wherton J, Greenhalgh T et al. Physical examinations via video for patients with heart failure: qualitative study using conversation analysis. J Med Internet Res 2020;22:e16694.

51 Roberts A, Blunt I, Bardsley M. Focus on: distance from home to emergency care. Nuffield Trust, The Health Foundation, 2014.

52 NHS Digital. Hospital Outpatient Activity, 2016-17. NHS, 2017. https://digital.nhs.uk/data-and-information/publications/statistical/ hospital-outpatient-activity/hospital-outpatient-activity-2016-17 [Accessed 02 April 2020].

53 NHS Digital. Appointments in General Practice, October 2018. NHS, 2018. https://digital.nhs.uk/data-and-information/publications/ statistical/appointments-in-general-practice/oct-2018 [Accessed 03 April 2020]. 
54 Portnoy ], Waller M, Elliott T. Telemedicine in the era of COVID-19. J Allergy Clin Immunol Pract 2020;8:1489-91.

55 Ohannessian R, Duong TA, Odone A. Global telemedicine implementation and integration within health systems to fight the COVID-19 pandemic: a call to action. JMIR Public Health Surveill 2020;6:e18810.

56 Greenhalgh T, Koh GCH, Car ]. Covid-19: a remote assessment in primary care. BMJ 2020;368:m1182.
57 Liu S, Yang L, Zhang C et al. Online mental health services in China during the COVID-19 outbreak. Lancet Psychiatry 2020;7:e17-8.

Address for correspondence: Amy Purohit, 53 Suez Road, Cambridge CB1 3QD, UK.

Email: amypurohit@hotmail.co.uk 